\title{
Changing commuters' mobility behaviors of university campuses: environmental and energy comparisons
}

\author{
Laura Cirrincione ${ }^{1, *}$, Salvatore Di Dio ${ }^{2}$, Maria La Gennusa ${ }^{1}$, Giorgia Peri ${ }^{1}$, Gianfranco \\ Rizzo $^{1}$, and Gianluca Scaccianoce ${ }^{1}$ \\ ${ }^{1}$ Department of Engineering, University of Palermo, Viale delle Scienze Bld. 9 Palermo, Italy \\ ${ }^{2}$ Department of Architecture University of Palermo, Viale delle Scienze Bld. 14 Palermo, Italy
}

\begin{abstract}
Governments are required to take proper measures to promote the use of electric and hybrid vehicles and, more generally, to push people towards sweeter modalities including walking and biking. To reach such tight and challenging goals, local institutions should be deeply involved, and universities among them. The promotion of sustainable mobility practices among commuter students must be considered indeed an effective contribution to facilitating the transition towards greener cities. On purpose, students of the University of Palermo that daily commute from their residences to the campus are considered here. These commuters, in fact, mainly adopt traditional polluting transportation means. Avoiding the recourse to these means by supporting the use of sweeter modalities such as walking, biking, public transport and vehicle pooling and sharing, would contribute to significantly reducing the associated polluting emissions. This task might be accomplished by involving students in app-based games that would reward their greener mobility behaviors. Results of a couple of in-field campaigns including a significant sample of commuter students is presented here, along with the obtainable environmental and energy benefits. The proposed method thus candidates itself as an effective tool that not only academic institutions but also local administrations could adopt to make their decarbonization pathways. Finally, it is argued whether universities (as well as local administrations) could be candidate for carbon or energy credits within the existing trading schemes because of the reduction of their energy consumption and greenhouse gases release.
\end{abstract}

Keywords: sustainable mobility; universities; commuter students; appbased tools.

\footnotetext{
* Corresponding author: laura.cirrincione@unipa.it
} 


\section{Nomenclature}

$\mathrm{m}=$ subscript index of modalities of mobility

$\mathrm{z}=$ subscript index of zones

$\mathrm{NC}=$ number commuters

$\mathrm{Wd}=$ yearly working days

$\mathrm{N}_{\mathrm{m}}=$ number of mobility modalities

$\mathrm{N}_{\mathrm{z}}=$ number of zones

$\mathrm{NC}_{z}=$ Number of commuters per zone

$\mathrm{EF}=$ Energy consumption factor $\left[\right.$ toe $\left./ \mathrm{t}_{\mathrm{co}}\right]$

$\mathrm{OR}_{\mathrm{m}}=$ Occupation rate per modality [passengers/vehicle]

$\mathrm{Em}=$ Emission factor of vehicles $[\mathrm{gCO} / \mathrm{km}]$

$\mathrm{MS}_{\mathrm{zm}}=$ Share of commuter per zone $(\mathrm{z})$ and modality $(\mathrm{m})$

$\mathrm{L}_{z \mathrm{c}}=$ Daily round trip per commuter $[\mathrm{km}]$

$\mathrm{C}_{\mathrm{zm}}=$ Daily energy consumption per zone (z) and modality of mobility (m) [toe]

$\mathrm{E}_{\mathrm{zm}}=$ Daily $\mathrm{CO}_{2}$ emissions per zone, modality and occupation rate $\left[\mathrm{tCO}_{2}\right]$

$\mathrm{TLzm}=$ Daily trip per zone and modality $[\mathrm{km}]$

$\mathrm{NC}_{\mathrm{zm}}=$ Number of commuters per zone and modality

\section{Introduction}

European Union's recommendations to member states for reduction of greenhouse gases emissions and fossil fuels' depletion seem to consider mainly power and heat generation sites and energy-intensive industries. Specifically, a decrease of $40 \%$ of $\mathrm{CO}_{2}$ emissions, compared to those released in the year 1990, should be reached at the year 2030 by these significant energy consuming plants. Unfortunately, member states are missing their own targets. Country projections, in fact, show that the EU emissions' decrease could reach a value of only $30 \%$ (without further interventions) by 2030, which is far from the expected target [1]. Obviously, such sites are of paramount importance to the accomplishment of the cited goals. Anyway, it must be considered that a relevant part of the energy consumption and, consequently, of the environmental pollution of countries, is attributable to other important sectors of the human lives such as the building and the transportation ones. The latter, according to the International Energy Agency [2], is believed to be responsible for $36 \%$ of the total energy consumption in the year 2017 , of which the $21 \%$ is imputable to passenger cars and the $15 \%$ to freight roads and other transportations. In Italy, in the same year, the energy consumption of the transportation sector accounted for 39.4 Mtoe, that is $33.8 \%$ of the total country's figure (apart from the huge changes in the energy demand and pollutant emissions of this sector induced by the Covid-19 pandemic emergency, not yet well accounted for).

In light of these data, several analyses have been carried out [3, 4] aimed at making the road traffic more environmentally sustainable by improving the road infrastructure [5], thus making the entire compartment more efficient and effective [6, 7]. Anyway, users' behaviors regarding their mobility modes (which is the topic of the present study) have received less attention to date, apart from a few researches that examined possible modifications in the mobility of cities. Therefore, governments are called to assume effective measures aimed at improving the mobility of people, shifting towards electric and hybrid vehicles and, more generally, sweeter modalities including walking and biking. In order of reaching such tight and challenging goals, local institutions should be also involved, and universities among them. Since the commuting of students represents an important component of the mobility, induced by academic activities, practices aimed at promoting sustainable student mobility must be considered an effective contribution to facilitating the needed transition towards greener cities. 
On purpose, the mobility of students of the University of Palermo that daily commute from their residences to the campus are considered here.

The study is well contextualized within a general policy that the University of Palermo has been currently developing [8]. In fact, starting from the year 2010, the University of Palermo has decided to embark on an effective energy saving path aimed at limiting the use of fossil fuels, in order to contribute to meeting the target proposed by the EU [9, 10] and the United Nations' Sustainable Development Goals - SDGs [11]. As for these latter, particularly SDGs numbers 7 [12] and 11 [13] were assumed as a guide, as they focus on the promotion of energy efficiency, environmental sustainability, safety and resilience, which are items of utmost importance for the university sector.

Moreover, the possibility that the university uses the saved amount of released $\mathrm{CO}_{2}$ within the existing Italian carbon market will be shortly discussed.

\section{Materials and Methods}

Consideration on the promotion of sustainable modes of transport associated to university campuses as an effective strategy to facilitate a transition towards greener and low carbon cities is not new: recently, this has been an important matter of scientific interest $[14,15,7]$. This transition could be accomplished, for instance, by involving students in app-based games that reward their greener mobility behaviors [16]. Within this conceptual frame, the paper reports on an experimental investigation whose subjects are the commuter students daily reaching the campus of the University of Palermo in Sicily (Southern Italy). This study is well contextualized within the wider policies pursued by the University of Palermo to greener its activities [17, 18].

The commuters considered here, actually, adopt traditional polluting mobility modalities. Figure 1 depicts the structure of the analyzed system, where the different modalities used by the students to reach the university campus from their residences are indicated. Clearly, the transportation mean used depends on both the preferences of commuters and the distance between the origin points and the campus.

Obviously, cutting the recourse to private and highly pollutant transportation means by supporting the use of sweeter modalities, such as walking, biking, public transport and vehicle pooling and sharing, would contribute to a significant reduction of the polluting emissions. In more detail, the minor the use of private and greatly polluting transportation means is, in favor of more sustainable modes (i.e. walking, biking, public transport and vehicle pooling and/or sharing), the greater the drop in polluting emissions would be [19].

The actual configuration (scenario 0 ) of the commuters' mobility has been defined using a survey conducted by the University on the origin-destination paths followed by students, who daily travel to the campus in order to attend courses (Figure 2, left side). It turned out that commuters account for nearly 25,000 and that for the majority of them four distance's zones can be identified, approximately circular areas spanning at 3, 5, 10 and $20 \mathrm{~km}$ far from the campus. A remaining part of the students lives at a distance greater than $20 \mathrm{~km}$ from the campus: these students have resulted to daily travel a mean distance of $60 \mathrm{~km}$ (students living at higher distances are not commuters [20] because they usually stay in rented rooms nearby the university campus). 


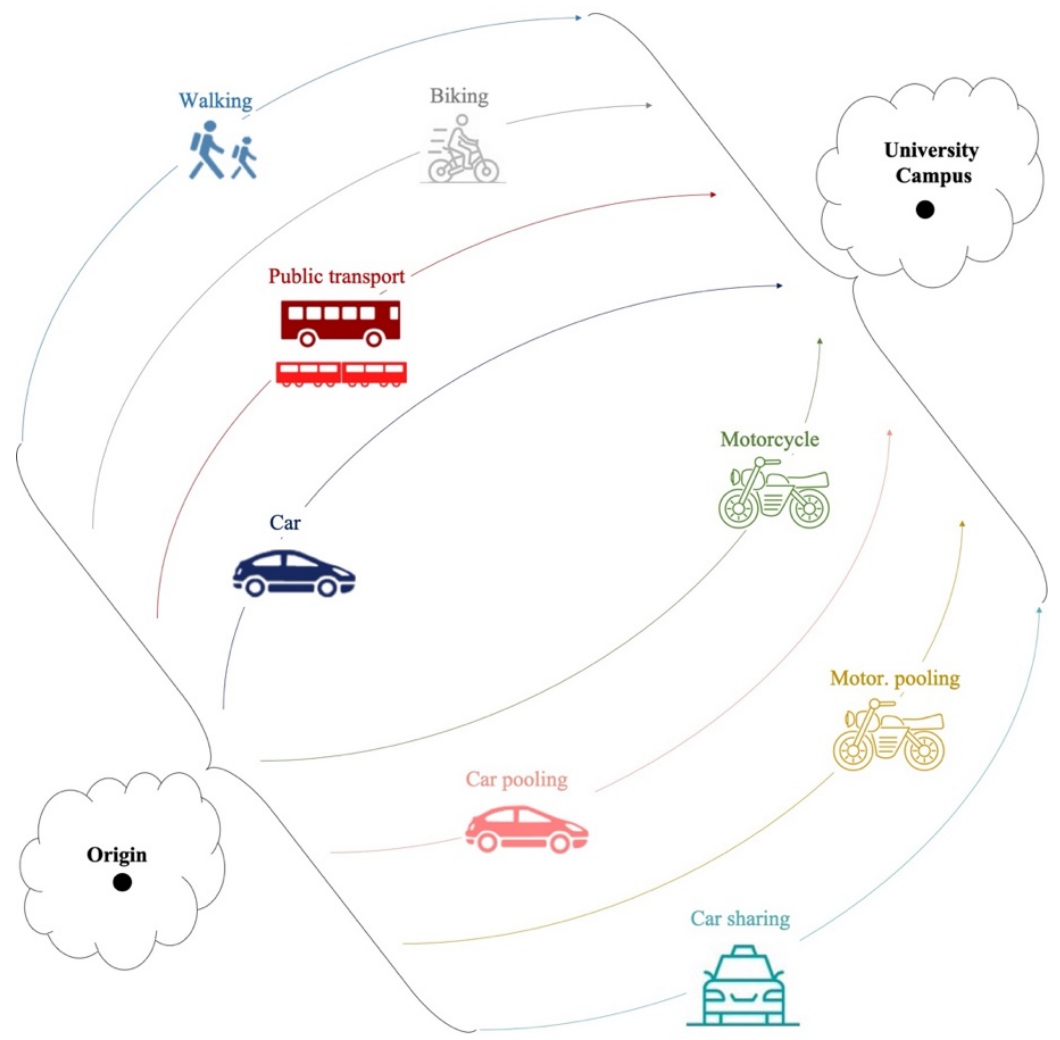

Fig. 1. Origin-destination segments covered by commuter students with different mobility modalities.

In order of assessing the effectiveness of different configurations of the mobility structure, the system needs to be mathematically modelled. The structure of this model is quite simple. The reasoning behind the model configuration starts from the knowledge of the number of commuters belonging to each distance's zone, $\mathrm{NC}_{z}$, and from the estimation of the daily round trip covered by each commuter, Lzc. This allows the evaluation of the total length of daily trips per zone, $\mathrm{TL}_{z}$, and of the number of commuters per zone and modality, $\mathrm{NC}_{z m}$. That is:

$$
\begin{aligned}
& \mathrm{TL}_{\mathrm{z}}=\mathrm{NC}_{\mathrm{z}} * \mathrm{~L}_{\mathrm{zc}} \\
& \mathrm{NC}_{\mathrm{zm}}=\mathrm{MS}_{\mathrm{zm}} * \mathrm{NC}_{\mathrm{z}}
\end{aligned}
$$

where $\mathrm{MS}_{\mathrm{zm}}$ represents the rate of the commuters per zone (subscript $\mathrm{z}$ ) and modality (subscript $\mathrm{m}$ ).

Therefore, the total length TLzm of the daily trip per each zone and each modality can be calculated as follows:

$$
\begin{aligned}
& \mathrm{TL}_{\mathrm{zm}}=\mathrm{MS}_{\mathrm{zm}} * \mathrm{TL}_{\mathrm{z}} \\
& \mathrm{TL}_{\mathrm{zm}}=\mathrm{NC}_{\mathrm{zm}} * \mathrm{~L}_{\mathrm{zc}}
\end{aligned}
$$

The daily $\mathrm{CO}_{2}$ emissions per zone, per modality and per occupation rate, Ezm, can be obtained as follows: 


$$
\mathrm{E}_{\mathrm{zm}}=\mathrm{TLzm} * \mathrm{E}_{\mathrm{m}} / \mathrm{ORm}
$$

where $\mathrm{E}_{\mathrm{m}}$ is the emission factor [21] of each typology of vehicles $\left[\mathrm{gCO}_{2} / \mathrm{km}\right.$ ] and $\mathrm{ORm}$ is the occupation rate per each mode of mobility [passengers/vehicle].

Finally, the daily energy consumption, $\mathrm{C}_{\mathrm{zm}}$, per zone $(\mathrm{z})$ and per modality of mobility (m) [toe] can be expressed as:

$$
\mathrm{C}_{z \mathrm{~m}}=\mathrm{E}_{z \mathrm{~m}} * \mathrm{EF}
$$

being EF the energy consumption factor [toe/t $\left.\mathrm{CO}_{2}\right]$.

By means of this simple model, the effects of a few on-field app-based campaigns, involving a significant sample of the commuter students, have been computed. Particularly, in terms of obtainable environmental and energy benefits related to greener mobility behaviors compared with the starting (actual) configuration of the commuters' mobility.

\section{Results}

As it is possible to see in the left side of Table 1 (referring to the starting scenario), typically private polluting means of transportation, such as cars and motorcycles, constitute the predominant part of the mobility, despite some travels take place by bike or on foot.

Hence, the environmental performance of the mobility structure can be largely improved by encouraging more sustainable commuting behaviors among students.

To achieve this target, the use of new information and communication technologies may effectively facilitate the communication between the university governance and the commuter students [22]. In these types of tools, users are the core of the technology. Nowadays, among the most effective choices app-based devices for smartphones can be cited $[23,24]$. On purpose, and with reference to the conditions of the commuters of the University of Palermo, a smartphone app has been developed [25]. The app is based on an info-mobility Decision Support System (TrafficO2), whose project (a social innovation one) was conducted by the PUSH design lab from 2013 to 2016; the Italian Ministry of University and Research co-financed the project. The main idea behind this mobile app is to enhance the traffic condition and limit air pollution through a social game, which would directly encourage citizens toward more environmentally conscious actions in a one-to-one dialogue. Making the interaction among pre-defined categories of users, companies and potential sponsors easier, as to achieve an agreement fair to all of them and offering rewards based on the use of sustainable transportation means, was one of the main goals of the service.

Specifically, commuters can get "environmental points" based on the number of $\mathrm{km}$ travelled and the selected mean of transport. The weather conditions are considered by the app as well, and in case of adverse conditions (e.g. windy and/or rainy weather), extra points are assigned. The individual mobility mode (that represents the actual movement made by the commuter) is gained using several algorithms which embed data collected from mobile devices currently present in the smartphones such as accelerometers or gyroscopes, or software components such as activity recognition.

To assess to what extent the TrafficO2 app is capable of encouraging commuter students to assume greener mobility modes by means of emulative games, firstly a test of the method was performed in the field. Specifically, a limited number of commuter students was asked to install the mobile app and take part to the challenge [25]. The new percentages of mobility, MS', per distances and transportation mode, obtained by testing this sample of students, are listed in Table 1, where the percentages have been aggregated by mobility 
modality. That is, walking + biking, public transportation, car + motorcycles, and vehicles pooling and sharing.

Table 1. Shares of the aggregate mobility modalities in the scenarios 0 and 1 (percentages).

\begin{tabular}{|c|c|c|c|c|c|c|c|c|c|c|}
\hline \multirow{3}{*}{$\begin{array}{l}\text { Aggregate } \\
\text { modalities }\end{array}$} & \multicolumn{10}{|c|}{ Distance of origins from the campus } \\
\hline & \multicolumn{2}{|c|}{$<3 \mathbf{k m}$} & \multicolumn{2}{|c|}{$3 \div 5 \mathrm{~km}$} & \multicolumn{2}{|c|}{$5 \div 10 \mathrm{~km}$} & \multicolumn{2}{|c|}{$10 \div 20 \mathrm{~km}$} & \multicolumn{2}{|c|}{$>20 \mathrm{~km}$} \\
\hline & Sc. 0 & Sc. 1 & Sc. 0 & Sc. 1 & Sc. 0 & Sc.I & Sc. 0 & Sc.1 & Sc.0 & Sc. 1 \\
\hline Walking+biking & $74 \%$ & $79 \%$ & $52 \%$ & $75 \%$ & $4 \%$ & $17 \%$ & $0 \%$ & $0 \%$ & $0 \%$ & $0 \%$ \\
\hline Public transp. & $10 \%$ & $10 \%$ & $13 \%$ & $13 \%$ & $25 \%$ & $32 \%$ & $19 \%$ & $22 \%$ & $34 \%$ & $48 \%$ \\
\hline Car+motorcycle & $5 \%$ & $0 \%$ & $23 \%$ & $0 \%$ & $46 \%$ & $6 \%$ & $44 \%$ & $23 \%$ & $38 \%$ & $13 \%$ \\
\hline $\begin{array}{l}\text { Vehicles } \\
\text { pooling and } \\
\text { sharing }\end{array}$ & $11 \%$ & $11 \%$ & $12 \%$ & $12 \%$ & $25 \%$ & $45 \%$ & $37 \%$ & $55 \%$ & $28 \%$ & $39 \%$ \\
\hline
\end{tabular}

By comparing data of Table 1 (also graphically reported in Figure 2), it is relevant to note the significant change in the ways in which students would move to the campus following the solicitations proposed by the smartphone-based rewarding scheme. Particularly, the most important modifications occur for walkers in the zones 3 and $5 \mathrm{~km}$ distant from the campus, change going from 32\% to 55\% (Figure 2). Polluting mobility, such as individual cars and motorcycles' use, seems to be mostly abandoned in the new scenario, in favor of the correspondent pooling and sharing versions, which are indeed characterized by interesting increasing percentages. In summation, the effectiveness of the smartphone app in inducing commuters towards less impacting modalities of mobility seems to be confirmed.

In order of estimating the overall impact of the new configuration of mobility, the outcomes relating to the sample of students have been tentatively extended to the entire campus commuters' community.

Figures 3 and 4 report a comparison between the two scenarios regarding the environmental $\left(\mathrm{CO}_{2}\right.$ emissions) and the energy (tons of equivalent oil) results, respectively; in reference to the five singled out origin-destination path zones.

Energy and environmental performances of both scenarios can be synthetically reported in terms of daily emissions of $\mathrm{CO}_{2}$ and daily consumption of fossil fuels ( $\mathrm{kg}$ of equivalent oil - keo) by each commuter. Table 2 reports this comparison by single commuter. The improvement produced by the application of the app-based tool is well evident. 


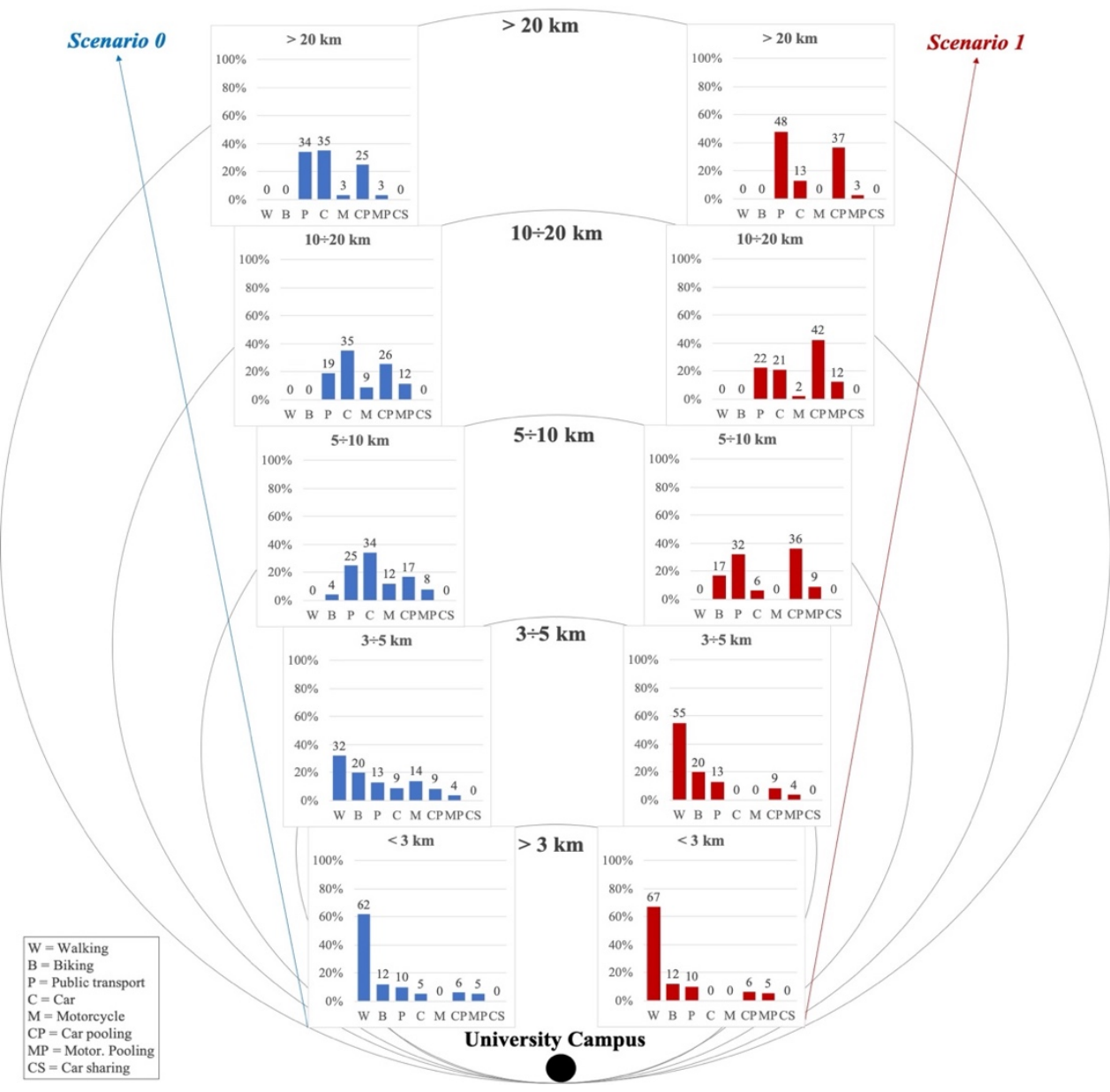

Fig. 2. Sketch of the distances from the campus of the origins of commuters.

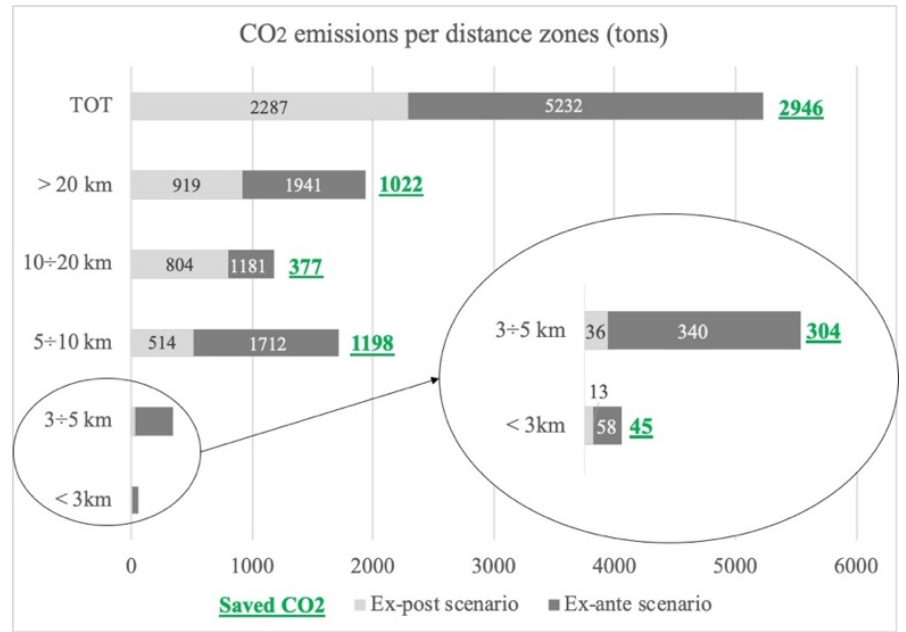

Fig. 3. Yearly $\mathrm{CO}_{2}$ (tons) releases and saved in the ex-ante (0) and improved (1) scenarios. 


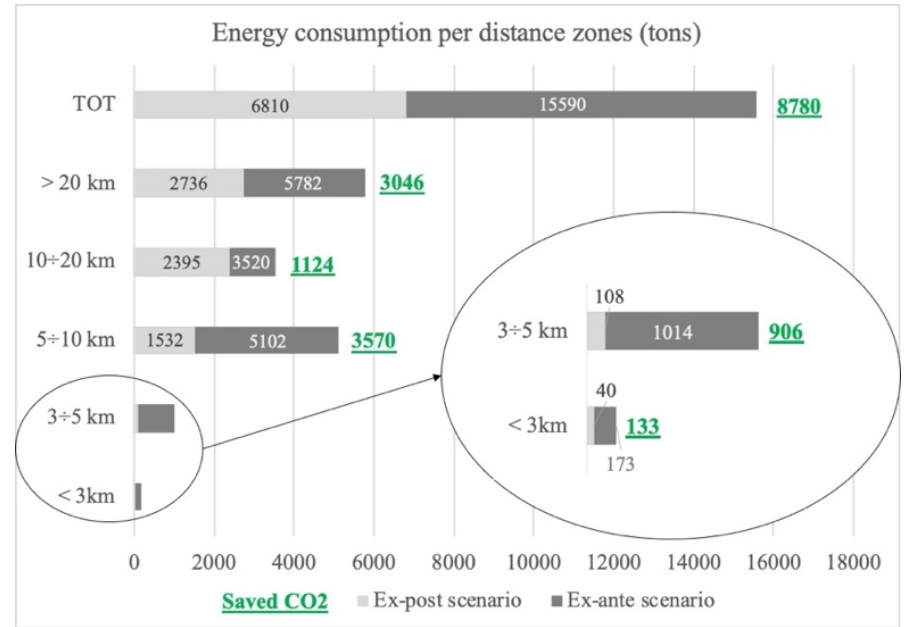

Fig. 4. Yearly fossil fuels energy amounts (toe) involved in the ex-ante (0) and improved (1) scenarios.

Table 2. Overall energy and environmental comparisons of the considered mobility scenarios.

\begin{tabular}{cl|cl}
\hline \multicolumn{2}{c|}{ Scenario 0 } & \multicolumn{1}{c}{ Scenario 1 } \\
\hline 1.070 & $\mathrm{~kg} \mathrm{CO} /$ day/commuter & 0.484 & $\mathrm{~kg} \mathrm{CO} /$ day $/$ commuter \\
2.884 & $\mathrm{keo} /$ day/commuter & 1.305 & $\mathrm{keo} / \mathrm{day} /$ commuter \\
\hline
\end{tabular}

\section{Discussion}

The study here presented describes some good practices that universities can implement to induce their users to undertake more virtuous actions and behaviors from both an environmental and health point of view. The hypothesis is supported by an analysis regarding the mobility habits of a sample of commuter students at the University of Palermo.

It must be underlined that the improvement of the energy and environmental performances of the commuters' mobility system, obtained by using the app-based tool for smartphones, relies on the assumption that the result of the sample of students involved in the here described field application, may be extended to the totality of the commuters gravitating around the university campus. This assumption, of course, should be further verified in the field.

Apart from the energy and environmental improvements that the mobility configuration of the scenario 1 would determine, it is here further argued whether the reduction of the energy consumption and the greenhouse gases release, could appoint universities (and, more in general, local administrations) to be rewarded with carbon or energy credits under the existing trading schemes [16].

Such hypothesis is based on the "trading" of the benefits that governments (or local authorities) could recognize to those who implement savings and/or energy efficiency actions, which translate into a reduction in polluting emissions deriving from their activities. These benefits could, for instance, include higher monetary state transfers (the 
so-called FFO for the Italian universities) or access to reduced prices for energy services and/or supplies.

Specifically, the opportunity to include the universities in the trading scheme of energy efficiency credits is taken into consideration here and, particularly, the chance to attain these credits is contextualized within the Italian "TEE" system ("Energy Efficiency Credits"). The hypothesis suggested here is of converting the reduced greenhouse gases emissions into energy efficiency credits [26], which the given university might then use to enter the carbon market. Precisely, the proposal advanced here suggests that the greener and more energy efficient behaviors adopted by the campus users (mainly students) might be indirectly attributed to the university that would benefit from the afore-mentioned credits. In fact, despite they would not actually be directly applicable in the actual credit scheme, the proposed actions could however be included amongst the so-called "behavioral" actions recommended by the EU $[27,28]$. An insubstantial modification of the current incentive mechanism would suffice, on purpose.

Additionally, the approach proposed in this study could bring benefits not only to the university but also to students participating to the program, who might get taxes reduction as well free access to services provided by the university.

Clearly, this proposal may be usefully adopted not only by universities but also by local administrations and public institutions in general.

Furthermore, from the performed study, some considerations may also be raised regarding the proper contextualization of the proposal, the economic value of the credits and the role of the institutions in pushing citizens towards more sustainable and resilience behaviors.

In fact, practices such as the one here proposed suitably spread throughout the territory could contribute to the process of improving the sustainability condition of an entire country, by properly involving citizens in the building-up of the so-called "Renewable Energy Communities", as suggested by the EU [27, 28].

Moreover, not by chance (and perfectly in line with what is proposed here) some European projects are currently active which, as part of the Horizon 2020 calls [29], promote - such as the scheme introduced here - gamified platforms in order of fostering energy communities.

\section{Conclusions}

A method based on an app for smartphones that rewards participants with a particular score has been presented here; this method is aimed at inducing commuter students to modify their mobility habits, addressing them towards means of transportation characterized by a lower environmental impact.

An application of the method to a sample of commuter students of the University of Palermo has shown its effectiveness from the environmental and energy points of view.

Moreover, a proposal to allow universities to enter the existing energy credit markets on the basis of obtainable benefits that is acquiring the white certificates corresponding to such benefits, has been advanced. In addition, the commuter students could be rewarded with services regarding their academic and campus-based activities.

Due to its easy scheme of application, the proposed method candidates itself as an effective tool that not only academic institutions but also local administrations could adopt in their paths towards decarbonized configurations. 


\section{References}

1. EEA, 2019. Total greenhouse gas emission trends and projections in Europe. https://www.eea.europa.eu/data-and-maps/indicators/greenhouse-gas-emission-trends7/assessment (accessed 18 February 2021).

2. IEA, 2020. Statistics Report on energy efficiency indicators. Highlights. https://www.iea.org/reports/energy-efficiency-indicators (accessed 18 February 2021).

3. Corriere, F., Rizzo, G., Guerrieri, M., 2013a. Estimation of air pollutant emissions in "turbo" and in conventional roundabouts. Appl. Mech. Mater. 394: 597-604. https://doi.org/10.4028/www.scientific.net/AMM.394.597.

4. Corriere, F., Peri, G., Rizzo, G., La Rocca, V., 2013b. Environmental implications of traffic flow delays: a model for urban streets. Appl. Mech. Mater. 260, 1167-1172. DOI: 10.4028/www.scientific.net/AMM.260-261.1167.

5. Guerrieri, M., Corriere, F., Lo Casto, B., Rizzo, G., c Scaccianoce, G. Improving the sustainability of transportation: environmental and functional benefits of right-turn by pass lanes at roundabouts. Sustainability 2015, 7 (5), 5838-5856.

6. Melkonyan, A., Koch, J., Lohmar, F., Kamath, V., Munteanu, V., Schmidt, J. A., Bleischwitz, R., 2020. Integrated urban mobility policies in metropolitan areas: A system dynamics approach for the Rhine-Ruhr metropolitan region in Germany. Sustain. Cities Soc. 61, 102358. https://doi.org/10.1016/j.scs.2020.102358.

7. Nematchoua, M. K., Deuse, C., Cools, M., Reiter, S., 2020. Evaluation of the potential of classic and electric bicycle commuting as an impetus for the transition towards environmentally sustainable cities: A case study of the university campuses in Liege, Belgium. Renew. Sust. Energ. Rev. 119, 109544.

8. Guerrieri, M., La Gennusa, G., Peri, G., Rizzo, G. Scaccianoce. University campuses as small-scale models of cities: Quantitative assessment of a low carbon transition path. Renewable and Sustainable Energy Reviews 2019. Volume 113.

9. Communication from the Commission to the European Parliament, the Council, the European Economic and Social Committee and the Committee of the Regions. A policy framework for climate and energy in the period from 2020 to 2030 . $\operatorname{COM}(2014)$ 15 final. Brussels.

10. Energy Roadmap 2050 of the European Commission. https://ec.europa.eu/clima/policies/strategies/2050_en (accessed 18 February 2021).

11. The UN Sustainable Development Goals. https://www.un.org/sustainabledevelopment (accessed 18 February 2021).

12. Sustainable Development Goal 7: Ensure access to affordable, reliable, sustainable and modern energy for all. https://www.un.org/sustainabledevelopment/energy/ (accessed 18 February 2021).

13. Sustainable Development Goal 11: Make cities inclusive, safe, resilient and sustainable. https://www.un.org/sustainabledevelopment/cities (accessed 18 February 2021).

14. Ribeiro, P., Fonseca, F., Meireles, T., 2020. Sustainable mobility patterns to university campuses: Evaluation and constraints. Case Studies on Transport Policy. 8 (2), 639647.

15. Dell'Olio, L., Cordera, R., Ibeas, A., Barreda, R., Alonso, B., Moura, J.L., 2019. A methodology based on parking policy to promote sustainable mobility in college campuses. Transp. Policy. 80, 148-156.

16. Di Dio, S., Massa, F., Nucara, A., Peri, G., Rizzo, G., Schillaci, D., 2020. Pursuing softer urban mobility behaviors through game-based apps. Heliyon. 6, e03930. https://doi.org/10.1016/j.heliyon.2020.e03930. 
17. Website of the University of Palermo. Data on departments, degree courses and student enrollment at the University of Palermo. https://www.unipa.it (accessed 18 February 2021).

18. Bisegna, F.; Cirrincione, L.; Maini, B.L.C.; Peri, G.; Rizzo, G.; Scaccianoce, G.; Sorrentino, G. Fostering the energy efficiency through the energy savings: The case of the University of Palermo. In Proceedings of the 2019 IEEE International Conference on Environment and Electrical Engineering and 2019 IEEE Industrial and Commercial Power Systems Europe, Palermo, Italy, 11-14 June 2019.

19. Di Dio, S., La Gennusa, M., Peri, G., Rizzo, G., Vinci, I., 2018. Involving people in the building up of smart and sustainable cities: How to influence commuters' behaviors through a mobile app game. Sustain. Cities Soc. 42, 325-336.

20. Studenti e bacini universitari. Istituto nazionale di statistica, Roma. (in Italian) ISBN 978-88-458-1909-4. https://www.istat.it/it/files/2016/11/Studenti-e-baciniuniversitari.pdf (accessed 18 February 2021).

21. Statistics of IEA for $\mathrm{CO} 2$ emissions from fuel combustion. http://energyatlas.iea.org (accessed 19 February 2021).

22. Marino, C., Nucara, A., Peri, C., Pietrafesa, M., Pudano, A., Rizzo, G., 2015. An MAS-based subjective model of indoor adaptive thermal comfort. Sci Technol. Built. En. 21, 114-125.

23. Ben-Elia, E., Erev, I., Shiftan, Y., 2008. The combined effect of information and experience on drivers' route-choice behavior. Transportation 35 (2):, 165-177.

24. Attard, M., Camilleri, M.P.J., Muscat, A., 2020. The technology behind a shared demand responsive transport system for a university campus. Research in Transportation $\quad$ Business \& $\quad$ Management. 36, 100463. https://doi.org/10.1016/j.rtbm.2020.100463.

25. Di Dio, S., Lo Casto, B., Micari, F., Rizzo, G., Vinci, I., 2015. Mobility, Data and Behavior: The TrafficO2 Case Study, in Vesco, A., Ferrero, F. (Eds.), Handbook of Research on Social, Economic, and Environmental Sustainability in the Development of Smart Cities 2015, Hershey, PA: IGI Global, 382-406.

26. Energy Efficiency Credits (or white certificates) Italy. https://www.gse.it/servizi-perte/efficienza-energetica/certificati-bianchi (accessed 18 February 2021). (in Italian).

27. Dirextive (EU) 2018/410 of the European Parliament and of the Council of 14 March 2018 amending Directive 2003/87/EC to enhance cost-effective emission reductions and low-carbon investments, and Decision (EU) 2015/181.

28. Directive (EU) 2019/944 of the European Parliament and of the Council of 5 June 2019 on common rules for the internal market for electricity and amending Directive 2012/27/EU.

29. CORDIS, 2021. EU Commission website on EU funded projects. https://cordis.europa.eu/projects/it (accessed 9 July 2021). 